Н. М. Шалухо, Е. В. Лукаш, А. С. Коридорова

Белорусский государственный технологический университет

\title{
ПОЛУЧЕНИЕ И ИССЛЕДОВАНИЕ СВОЙСТВ АЛЮМОСИЛИКАТНЫХ СВЯЗОК ДЛЯ ЛЕГКОВЫБИВАЕМЫХ ЛИТЕЙНЫХ ФОРМ
}

Рассмотрена проблема выбиваемости металлических отливок из формовочных смесей и приведен анализ технических характеристик связующих, используемых в настоящее время в литейной технологии. Показано, что ни одна из систем связующих в настоящее время полностью не удовлетворяет предъявляемым к ним требованиям. Разработка связующей композиции, применение которой давало бы возможность получать формы с требуемой начальной прочностью в момент заливки расплавленного металла и деструкцией материала в момент остывания металла в форме, является актуальной. Одним из направлений регулирования эксплуатационных свойств формовочных смесей на жидкостекольных связующих является их модифицирование различными химическими реагентами, в частности получение алюмосиликатной связки. Целью исследования являлось получение алюмосиликатной связки, которая может быть использована в составе формовочных смесей для литейных форм. Установлены оптимальные количественные соотношения компонентов в алюмосиликатной связке (содержание алюминатного раствора - 30-

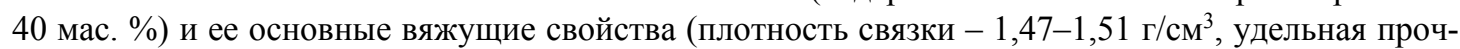
ность смеси после отверждения - 0,22-0,38). Высказано предположение о том, что алюмосиликатная связка создает в области $950-1200^{\circ} \mathrm{C}$ термические напряжения за счет несогласованности температурных коэффициентов линейного расширения новообразований с матрицей, приводящие к саморазрушению композиционного материала, тем самым снижает трудозатраты и облегчает выбивку металлических отливок.

Ключевые слова: алюмосиликатная связка, щелочной раствор, жидкое стекло, отвердитель, литейная форма, термоудар.

Для цитирования: Шалухо Н. М., Лукаш Е. В., Коридорова А. С. Получение и исследование физико-механических свойств алюмосиликатных связок для легковыбиваемых литейных форм // Труды БГТУ. Сер. 2, Химические технологии, биотехнологии, геоэкология. 2021. № 2 (247). C. 153-158.

\section{N. M. Shalukho, E. V. Lukash, A. S. Koridorova \\ Belarusian State Technological University \\ PREPARATION AND RESEARCH PROPERTIES OF ALUMINOSILICATE BINDERS FOR EASY-TO-BREAK CASTING MOLDS}

The problem of knockability of metal castings from molding mixtures is considered and the analysis of the technical characteristics of binders currently used in casting technology is given. The development of a binding composition, the use of which would make it possible to obtain molds with the required initial strength at the time of pouring the molten metal and the destruction of the material at the time of cooling of the metal in the mold, is an urgent task. One of the directions of regulating the operational properties of molding mixtures on liquid-glass binders is their modification by various chemical agents, in particular, the production of an aluminosilicate binder. The aim of the study was to obtain an alumino-silicate binder that can be used as a part of molding mixes for casting molds. The optimal quantitative ratios of the components in the aluminosilicate binder (the content of the aluminate solution is 30-40 wt. \%) and its main binding properties (the density of the binder is $1.47-1.51 \mathrm{~g} / \mathrm{cm}^{3}$, the specific strength of the mixture after curing is $0.22-0.38$ ). It is suggested that the aluminosilicate bond creates in the region of $950-1,200^{\circ} \mathrm{C}$ thermal stresses due to the inconsistency of the thermal coefficients of the linear expansion of the neoplasms with the matrix, leading to self-destruction of the composite material, thereby reducing labor costs and facilitating the knocking out of metal castings.

Key words: aluminosilicate binder, alkaline solution, liquid glass, hardener, mold, thermal shock.

For citation: Shalukho N. M., Lukash E. V., Koridorova A. S. Preparation and research properties of aluminosilicate binders for easy-to-break casting molds. Proceedings of BSTU, issue 2, Chemical Engineering, Biotechnologies, Geoecology, 2021, no. 2 (247), pp. 153-158 (In Russian). 
Введение. Одной из основных задач литейного производства является снижение трудовых, материальных и энергетических затрат при получении литых заготовок требуемого качества. В этой области важное значение приобретает совершенствование технологии приготовления формовочных и стержневых смесей. Это в первую очередь относится к изготовлению разовых форм, в которые в настоящее время производится основная масса отливок [1-3]. Производство литых металлических заготовок на специализированных предприятиях (ОАО «Гомельский литейный завод «Центролит», литейные цеха ОАО «Минский завод отопительного оборудования», а также крупные цеха на ОАО «МТЗ», ОАО «МАЗ», ОАО «Гомсельмаш» и др.) имеет весьма крупные масштабы. Важной технологической операцией на указанных производствах является изготовление литейных форм, которые представляют собой композиционный материал, состоящий из кварцевого песка определенного гранулометрического состава и различных видов связующих.

В качестве связующих наибольшее распространение получили карбамидоформальдегидные смолы, жидкое натриевое стекло, фосфатные связки и др. Каждый вид имеет как достоинства, так и недостатки [4]. Органические смолы в целом удовлетворяют требованиям по механическим и термическим свойствам, т. е. они обеспечивают достаточную прочность в момент заливки расплава металла, а после остывания металла формы относительно легко разрушаются и тем самым обеспечивается удовлетворительная выбиваемость. Серьезным недостатком является выделение в рабочую зону формальдегида, который относится к 1-му классу опасности. Очистка отливок при производстве литых заготовок в разовых формах с применением жидкостекольных смесей относится к тяжелым физическим работам, хотя вредных газовыделений не происходит. Ситуация усугубляется еще и тем, что данные операции, как правило, производятся в условиях повышенной запыленности воздуха рабочей зоны. Аналогичные проблемы возникают и при использовании фосфатных связующих $[1,5]$.

Одним из способов улучшения условий труда работников, занятых на производстве металлических отливок в разовые формы с использованием жидкостекольных смесей, является снижение трудоемкости выбивки и очистки отливок, а также уменьшение запыленности рабочей зоны [5-6]. Отверждение смесей на основе жидкого стекла происходит вследствие гелеобразования, в результате чего возникают прочные когезионные связи в самом связующем и адгезионные - в зернах песка. Отработанная жидкостекольная смесь, прогретая до температуры 930-950 ${ }^{\circ} \mathrm{C}$, после выбивки из отливок содержит кварцевые зерна, прочно сцементированные расплавом силиката натрия. Формирование структуры происходит в результате взаимодействия связки и наполнителя, что сопровождается определенными физико-химическими процессами, приводящими к возникновению растягивающих напряжений, разрушению зерен наполнителя и повышению пылевыделения при выбивании отливок и их очистке [7]. Таким образом, преимущества жидкого стекла по сравнению с другими связующими материалами очевидны. Но при этом центральной проблемой является затрудненная выбиваемость и регенерируемость жидкостекольных смесей.

Имеется большое количество исследовательских работ, посвященных формообразованию при использовании жидкостекольного связующего [1-8]. Указывается, что жидкостекольная связка наиболее полно удовлетворяет технологическим, экономическим и экологическим требованиям. Отмечается, что преимущества жидкостекольных смесей заключаются в их нетоксичности, негорючести, доступности и невысокой стоимости $[3,7]$.

Известно [7-8], что при использовании жидкостекольного связующего для приготовления литейных стержней и форм возможны следующие ситуации. При малом содержании связующего смеси имеют низкую прочность и высокую осыпаемость. При повышенном содержании связующего заметно возрастает прочность смесей после заливки металла в форму, что резко повышает трудоемкость выбивки и очистки отливок. Поэтому одним из способов улучшения свойств формовочных смесей является разработка такой связующей композиции, применение которой давало бы возможность получать стержни и формы с высокой начальной прочностью, но показатели которой снижались бы после заливки и остывания металла в форме.

Модифицирование жидкостекольных связующих обычно осуществляется за счет введения на стадии получения в их состав сульфата аммония, гидроксида или сульфата алюминия. Такой прием изложен во многих работах, где был применен принцип приготовления смешанных связующих композиций $[1,4-5,8-10]$. Связующую жидкостекольную композицию готовят смешиванием водных растворов силиката натрия с растворами солей, подвергающихся гидролизу, смол и эфиров. Это обеспечивает повышение вяжущей способности такого модифицированного жидкого стекла.

Алюмосиликатные связки получают смешением растворов силиката и алюмината натрия. Соотношение $\mathrm{Na}_{2} \mathrm{O} / \mathrm{Al}_{2} \mathrm{O}_{3}$ в алюминате составляет обычно 1,60-1,80. При сливании таких растворов 
образуются гели алюмосиликатов натрия. Отмечается, что активность связки достигает максимального значения при отношении алюмината к жидкому стеклу 30:70. Повышение концентрации алюминатного раствора уменьшает область смешиваемости [11-13].

Целью данной работы являлось получение алюмосиликатной связки и формовочной смеси на ее основе, обладающей требуемой прочностью в момент заливки расплавленного металла в формы, и ее потерей вследствие деструктивных процессов в момент остывания отливки.

Объектом исследования являлась алюмосиликатная связка и литейные композиции на ее основе.

Основная часть. На первом этапе исследований готовили щелочной раствор гидроксида алюминия путем растворения $\mathrm{Al}(\mathrm{OH})_{3}$ в 45\%ном растворе $\mathrm{NaOH}$ с плотностью $1,48 \Gamma / \mathrm{cm}^{3}$. Затем смешивали полученный щелочной алюми-

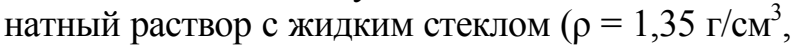
силикатный модуль 2,8) в следующих соотношениях: 20:80, 30:70 и 40:60.

Согласно литературным данным [1], получение связующих композиций на основе водного раствора силиката натрия и алюминатов базируется на комплексообразовании алюмосиликатных систем. При смешивании раствора каустической соды с гидроксидом алюминия возможно образование геля алюмината натрия $2 \mathrm{Na}\left[\mathrm{Al}(\mathrm{OH})_{4}\right]$. Водный раствор алюмината натрия является нестабильным и в щелочной среде проявляет коагулирующее действие. Добавление алюмината натрия в водный раствор силиката натрия приводит к их связыванию в алюминаты натрия типа анальцима $\left[\mathrm{Na}_{4}\left(\mathrm{OH}_{2}\right)_{4}\right] \cdot\left[\mathrm{Al}_{4} \mathrm{Si}_{8} \mathrm{O}_{24}\right]$.

$\mathrm{C}$ применением полученной алюмосиликатной связки были разработаны составы связующих композиций. В качестве наполнителя использовали кварцевый формовочный песок с массовой долей $\mathrm{SiO}_{2}$ не менее 93 мас. \% и глинистой составляющей не более 2,0 мас. \% [14]. Отвердителем композиции служил наиболее распространенный для этих целей кремнефторид натрия (5-20 мас. \%).

На первом этапе исследования соотношение наполнитель:алюмосиликатная связка составило 80:20

К связующим материалам, обеспечивающим необходимые прочностные свойства смесей в исходном и нагретом состояниях, предъявляется ряд требований [3]. Наиболее важным считается показатель удельной прочности $\left(\sigma_{\text {уд }}\right)$, который в литейном производстве характеризует эффективность связующего материала, обусловленную минимально необходимым содержанием связки в формовочной смеси, достаточным для обеспечения прочности формы в момент заливки расплавленного металла. Высокую удельную прочность имеют материалы с $\sigma_{\text {уд }}>0,5$, среднюю $-\mathrm{c} \sigma_{\text {уд }}=0,3-0,5$, низкую $-\mathrm{c} \sigma_{\text {уд }}<0,3$ [3]. Прочность формовочных смесей должна быть достаточной, чтобы обеспечить изготовление, транспортировку, хранение, сборку форм без повреждений или разупрочнения.

Свойства синтезированных алюмосиликатных связок отражены в таблице. Удельная прочность представляет собой отношение прочности на сжатие высушенного образца (температура сушки $-105 \pm 5^{\circ} \mathrm{C}$ ), полученного из смеси с определенным содержанием связующего и наполнителя, к процентному содержанию связующего в смеси.

\section{Свойства алюмосиликатных связок}

\begin{tabular}{|c|c|c|c|}
\hline $\begin{array}{c}\text { Номер } \\
\text { состава }\end{array}$ & $\begin{array}{c}\text { Объемное соотно- } \\
\text { шение алюминат- } \\
\text { ного раствора } \\
\text { к жидкому стеклу }\end{array}$ & $\begin{array}{c}\text { Плот- } \\
\text { ность, } \\
\text { г/с }\end{array}$ & $\begin{array}{c}\text { Удельная } \\
\text { прочность } \\
\text { смеси после } \\
\text { отверждения } \\
\sigma_{\text {уд }}\end{array}$ \\
\hline 1 & $20: 80$ & 1,47 & 0,22 \\
\hline 2 & $30: 70$ & 1,49 & 0,33 \\
\hline 3 & $40: 60$ & 1,51 & 0,38 \\
\hline
\end{tabular}

Как видно из таблицы, составы № 2 и 3 по показателю удельной прочности относятся к связующим средней эффективности. Таким образом, связки, полученные с соотношением алюминатного раствора к жидкому стеклу 30:70 и 40:60, могут быть использованы в составе формовочной смеси.

Следует отметить, что с увеличением содержания алюминатного раствора вязкость всех связок повышалась. Так, наименьшей вязкостью характеризовался состав с соотношением алюминатного раствора к жидкому стеклу 20:80, но и более низкой прочностью. Составы с большим содержанием алюминатного раствора показали более высокую прочность на сжатие и удовлетворительную смешиваемость. Дальнейшее исследование проводили на составах с содержанием алюминатного раствора в диапазоне 30-40 мас. \%.

На следующем этапе исследования определяли оптимальный состав композиции наполнитель - связка. Для этого смешивали наполнитель формовочный кварцевый песок с алюмосиликатной связкой и отвердителем $\mathrm{Na}_{2} \mathrm{SiF}_{6}$ до получения однородной массы (время перемешивания в лабораторном смесителе составляло 2-3 мин). Затем полученную смесь укладывали в металлические формы с ребром 20 мм. После отверждения образцы расформовывали и испытывали на прочность на сжатие. Для сравнения свойств композиций аналогичным образом готовили образцы на основе жидкостекольной связки. 
Для исследований приготавливали следующие составы формовочных смесей, мас. \%: формовочный кварцевый песок - 60-95; связка (алюмосиликатная или жидкостекольная) - 5-40; отвердитель (от массы связки) - 5-20.

Сформованные образцы испытывали на прочность на сжатие после их отверждения при комнатной температуре в течение суток. Установлено, что алюмосиликатная связка обеспечивает прочность на сжатие литейным композициям 3-7 МПа при ее содержании в составе смеси 5-20 мас. \%. В то время как образцы на жидкостекольной связке показали аналогичные значения прочности на сжатие при 25\%-ном ее содержании. Это является доказательством того, что вяжущая активность алюмосиликатной связки выше, чем у наиболее распространенной в использовании жидкостекольной связки.

Проблемным местом в технологии разовых отливок является трудная выбиваемость литейных смесей вследствие их пригорания к металлу $[3,5,15]$. В этой связи требовалось установить температурный диапазон разупрочнения образцов формовочных смесей.

Исследования образцов литейных композиций осуществляли в режиме термоудара при различных температурах. Образцы помещали в предварительно нагретую до заданных температур $\left(700-1200^{\circ} \mathrm{C}\right)$ муфельную печь с кратковременной выдержкой в течение 3-10 мин в зависимости от времени их полного разупрочнения.

Установлено, что в интервале температур $700-900^{\circ} \mathrm{C}$ все образцы (на алюмосиликатной и жидкостекольной связках) сохраняли остаточную прочность (рис. 1-2).

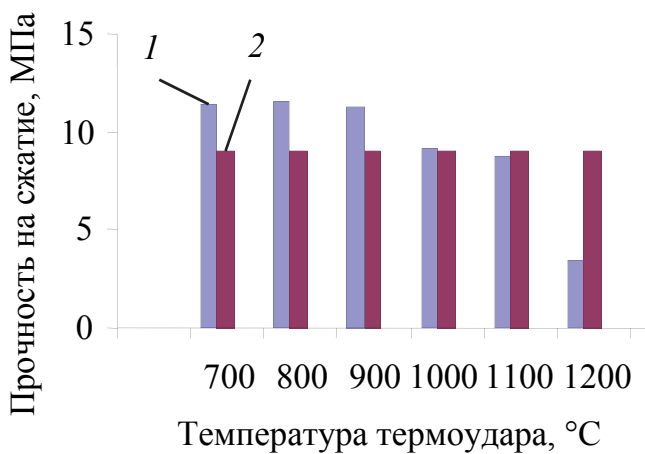

Рис. 1. Влияние температуры термоудара на прочность при сжатии образцов на жидкостекольной связке:

1 - образец после термообработки; 2 - образец до термообработки

Термоудар при более высоких температурах $\left(950-1200^{\circ} \mathrm{C}\right)$ приводил к разупрочнению, сопровождающемуся полным разрушением образцов на основе алюмосиликатной связки (рис. 2).

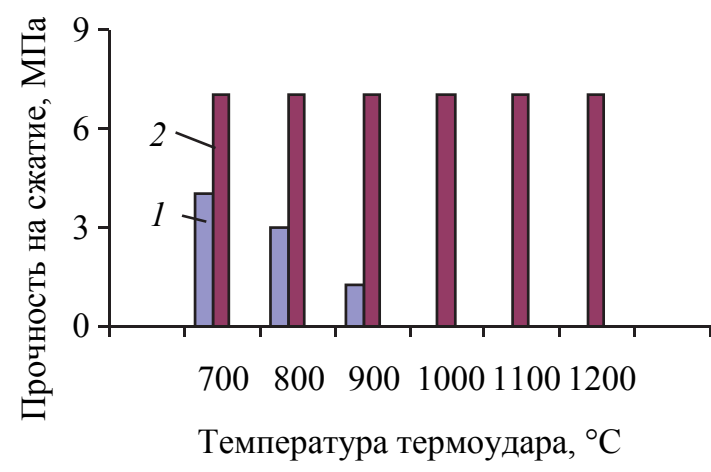

Рис. 2. Зависимость прочности при сжатии образцов на алюмосиликатной связке от температуры термоудара:

1 - образец после термообработки;

2 - образец до термообработки

В то же время литейные композиции на основе жидкостекольной связки не разрушались во всем температурном диапазоне тепловой обработки. С увеличением температуры нагрева остаточная прочность образцов сначала увеличивалась (прирост прочности составил до 20\%), т. е. наблюдалось некоторое их упрочнение в интервале температур $700-1000^{\circ} \mathrm{C}$, а затем в диапазоне $1000-1100^{\circ} \mathrm{C}$ прочность сохранялась на уровне первоначальной (до термоудара) и после $1200^{\circ} \mathrm{C}$ начиналось терморазупрочнение с существенным снижением прочности (до 60\%).

Согласно литературным данным [1], алюминаты натрия типа анальцима $\left[\mathrm{Na}_{4}\left(\mathrm{OH}_{2}\right)_{4}\right] \cdot\left[\mathrm{Al}_{4} \mathrm{Si}_{8} \mathrm{O}_{24}\right]$ плохо коррелируют в отношении согласования их температурного коэффициента линейного расширения (ТКЛР) и окружающей матрицы. Так, известно, что ТКЛР кварца в интервале температур от 20 до $1000^{\circ} \mathrm{C}$ составляет $5,4 \cdot 10^{-6} \mathrm{~K}^{-1}$, для $\mathrm{Na}_{2} \mathrm{SiO}_{3}-(17,6-19,2) \cdot 10^{-6} \mathrm{~K}^{-1}$ [1]. Как видно из приведенных данных, указанная разница в их значениях, по-видимому, является недостаточной для того, чтобы обеспечить удовлетворительную выбиваемость форм на жидкостекольной связке в отличие от алюмосиликатной.

Термохимические превращения, происходящие в композициях на основе алюмосиликатной связки, носят иной характер. Согласно [1], в интервале $900-950^{\circ} \mathrm{C}$ гидроксоалюминат щелочного металла подвергается термодеструкции с выделением $\gamma-\mathrm{Al}_{2} \mathrm{O}_{3}$ и едкой щелочи с последующим их взаимодействием. Образующееся при этом соединение $\mathrm{Na}_{2} \mathrm{O} \cdot \mathrm{Al}_{2} \mathrm{O}_{3}$ имеет высокую температуру плавления $\left(1650^{\circ} \mathrm{C}\right)$, что не приводит к образованию расплавленных силикатов, которые способны выполнять роль связующего компонента и упрочнять литейную форму после ее остывания. В целом можно отметить, что физико-химические процессы отверждения алюмосиликатных связующих достаточно сложны. 
Заключение. В работе приведен анализ научно-технических проблем, связанных с использованием различного рода связующих при получении литейных легковыбиваемых форм. Показана перспективность получения новых видов связующих, обеспечивающих достаточную механическую прочность литейным формам в момент заливки расплавленного металла, в частности для алюминиевых и магниевых сплавов, для которых эта температура составляет 700$780^{\circ} \mathrm{C}$. В процессе остывания формы происходящие в ней физико-химические превращения должны обеспечивать ее саморазрушение за счет образующихся термических напряжений. Установлено, что применение алюмосиликатной связки в качестве связующего компонента литейной композиции позволяет снизить содержание связки в составе смеси по сравнению с использованием жидкостекольной. Установлены оптимальные количественные соотношения компонентов в алюмосиликатной связке (содержание алюминатного раствора - 30-40 мас. \%) и ее основные вяжущие свойства (плотность

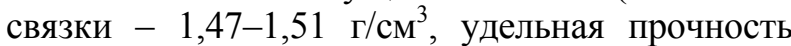
смеси после отверждения - 0,22-0,38). Определено, что в интервале температур $950-1200^{\circ} \mathrm{C}$ происходит разрушение композиции на основе алюмосиликатной связки, в то время как смеси на жидкостекольном связующем не претерпевали изменений.

\section{Список литературы}

1. Гурлев В. Г. Органо- и алюмосиликатные связующие композиции на основе жидкого стекла для изготовления стержней, форм и противопригарных покрытий: автореф. дис. ... д-ра техн. наук: 05.16.04. Челябинск, 2002. 42 с.

2. Middleton J. Steel foundry moulding materials // Brit. Foundryman. 1970. No. 7. P. 167-183.

3. Кукуй Д. М., Андрианов Н. В. Теория и технология литейного производства. Формовочные материалы и смеси. Минск: БНТУ, 2005. 361 с.

4. Гурлев В. Г. Алюмосиликатные связующие композиции для изготовления литейных форм и стержней при производстве литых заготовок и социально-экономическая оценка условий труда // Вестник ЮУрГУ. 2008. № 9. С. 44-50.

5. Применение модифицированного жидкостекольного связующего в целях улучшения условий труда выбивщиков / Ю. П. Васин [и др.] // Литейное производство. 1987. № 1. С. 29-30.

6. Васильев В. А. Физико-химические основы литейного производства. М.: Интермет Инжиниринг, 2001. $336 \mathrm{c}$.

7. Илларионов И. Е., Петрова Н. Е. Особенности применения жидкостекольных смесей // Вестник ЧГПУ имени И. Я. Яковлева. 2010. № 4 (68). С. 62-70.

8. Иткис 3. Я., Гурлев В. Г., Дворяшина Ю. С. Применение модифицированного жидкостекольного связующего для стержней, форм и противопригарных покрытий // Литейное производство. 1995. № 4-5. С. 40-41.

9. Гурлев В. Г., Дворяшина Ю. С. Теоретические основы приготовления органо- и алюмосиликатных связующих композиций для литейных стрежней и форм // Труды пятого съезда литейщиков России. М., 2001. С. 352-354.

10. Zaretskiy L. Modified silicate binders. New developments and applications // International journal of metalcasting. 2016. № 10. P. 88-99.

11. Сычев М. М. Неорганические клеи. М.: Химия, 1986. 152 с.

12. Кузьменков М. И., Шалухо Н. М. Технология специальных цементов и композиционных материалов технического назначения. Минск: БГТУ, 2014. 257 с.

13. Мохор О. Н., Лукаш Е. В., Кузьменков М. И. Получение алюмосиликатной связки для композиционных материалов технического назначения // 71-я науч.-техн. конф. учащихся, студентов и магистрантов: тез. докл.: в 4 ч. Минск, 20-25 апр. 2020 г. Минск, 2020. Ч. 2. С. 235-236.

14. Пески формовочные. Общие технические условия: ГОСТ 2138-91. М.: Стандартинформ, 2005. $5 \mathrm{c}$.

15. Евлампиев А. А., Чернышев Е. А., Королев А. В. Общие положения и рекомендации при выборе процессов приготовления и составов формовочных смесей // Литейное производство. 2005. № 8. C. 10-13.

\section{References}

1. Gurlev V. G. Organo- i alyumosilikatnyye svyazuyushchiye kompozitsii na osnove zhidkogo stekla dlya izgotovleniya sterzhney, form i protivoprigarnykh pokrytiy. Avtoref. dis. dokt. techn. nauk [Organo- and aluminosilicate binder compositions based on liquid glass for the manufacture of rods, molds and non-stick coatings. Abstract of thesis doct. techn. sci.]. Chelyabinsk, 2002. 42 p.

2. Middleton J. Steel foundry moulding materials. Brit. Foundryman, 1970, no. 7, pp. 167-183. 
3. Kukuy D. M., Andrianov N. V. Teoriya i tekhnologiya liteynogo proizvodstva. Formovochnyye materialy $i$ smesi [Theory and technology of foundry production. Molding materials and mixtures]. Minsk, BNTU Publ., 2005. $361 \mathrm{p}$.

4. Gurlev V. G. Aluminum-silicate binder compositions for the manufacture of casting molds and rods in the production of cast blanks and socio-economic assessment of labor conditions. Vestnik $Y u U r G U$ [Bulletin of SUSU], 2008, no. 9, pp. 44-50 (In Russian).

5. Vasin Yu. P., Bortnikov M. M., Kryukova I. V., Gurlev V. G. Application of the modified liquid-glass binder for the purpose of improving the working conditions of knockers. Liteynoye proizvodstvo [Foundry production], 1987, no. 1, pp. 29-30 (In Russian).

6. Vasiliev V. A. Fiziko-khimicheskiye osnovy liteynogo proizvodstva [Physical and chemical bases of foundry production]. Moscow, Intermet Engineering Publ., 2001. 336 p.

7. Illarionov I. E., Petrova N. E. Features of the use of liquid-glass mixtures. Vestnik ChGPU imeni I. Ya. Yakovleva [Bulletin of the I. Ya. Yakovlev ChSPU], 2010, no. 4 (68), pp. $62-70$ (In Russian).

8. Itkis Z. Ya., Gurlev V. G., Dvoryashina Yu. S. Application of modified liquid-glass binder for rods, molds and non-stick coatings. Liteynoye proizvodstvo [Foundry production], 1995, no. 4-5, pp. 40-41 (In Russian).

9. Gurlev V. G., Dvoryashina Yu. S. Theoretical foundations of the preparation of organo- and aluminosilicate binder compositions for casting rods and molds. Trudy pyatogo s"ezda liteyshchikov Rossii [Proceedings of the Fifth Congress of Foundry workers of Rossia]. Moscow, 2001, pp. 352-354 (In Russian).

10. Zaretskiy L. Modified silicate binders. New developments and application. International journal of metalcasting, 2016, no. 10, pp. 88-99.

11. Sychev M. M. Neorganicheskiye klei [Inorganic adhesives]. Moscow, Khimiya Publ., 1986. 152 p.

12. Kuzmenkov M. I., Shalukho N. M. Tekhnologiya spetsial'nykh tsementov i kompozitsionnykh materialov tekhnicheskogo naznacheniya [Technology of special cements and composite materials for technical purposes]. Minsk, BSTU Publ., 2014. 257 p.

13. Mahor O. N., Lucash E. V., Kuzmenkov M. I. Getting aluminosilicate chords for composite materials for technical purposes. 71-ya nauchno-tekhnicheskaya konferentsiya uchashchikhsya, studentov $i$ magistrantov: tezisy dokladov: $v 4$ chastyakh [71st scientific conference of students and undergraduates: in 4 parts]. Minsk, 2020, part 2, pp. 235-236 (In Russian).

14. GOST 2138-91. Moulding sands. General specifications. Moscow, Standartinform Publ., 2005. 5 p. (In Russian).

15. Evlampiev A. A., Chernyshev E. A., Korolev A. V. General provisions and recommendations for the selection of preparation processes and compositions of molding mixtures. Liteynoye proizvodstvo [Foundry production], 2005, no. 8, pp. 10-13 (In Russian).

\section{Информация об авторах}

Шалухо Наталия Михайловна - кандидат технических наук, доцент кафедры химической технологии вяжущих материалов. Белорусский государственный технологический университет (220006, г. Минск, ул. Свердлова, 13a, Республика Беларусь). E-mail: shalukho@belstu.by

Лукаш Елена Вацлавовна - кандидат технических наук, старший преподаватель кафедры химической технологии вяжущих материалов. Белорусский государственный технологический университет (220006, г. Минск, ул. Свердлова, 13a, Республика Беларусь). E-mail: ellukash@belstu.by

Коридорова Анастасия Сергеевна - студент. Белорусский государственный технологический университет (220006, г. Минск, ул. Свердлова, 13а, Республика Беларусь). E-mail: koridorova.as@gmail.com

\section{Information about the authors}

Shalukho Natalia Mikhailovna - PhD (Engineering), Assistant Professor, the Department of Chemical Technology of Binding Materials. Belarusian State Technological University (13a, Sverdlova str., 220006, Minsk, Republic of Belarus). E-mail: shalukho@belstu.by

Lukash Elena Vatslavovna - PhD (Engineering), Senior Lecturer, the Department of Chemical Technology of Binding Materials. Belarusian State Technological University (13a, Sverdlova str., 220006, Minsk, Republic of Belarus). E-mail: ellukash@belstu.by

Koridorova Anastasia Sergeevna - student. Belarusian State Technological University (13a, Sverdlova str., 220006, Minsk, Republic of Belarus). E-mail: koridorova.as@gmail.com 